University of Nebraska - Lincoln

DigitalCommons@University of Nebraska - Lincoln

\title{
Glocal integrity in 420 stainless steel by asynchronous laser processing
}

\author{
Michael P. Sealy \\ University of Nebraska-Lincoln, sealy@unl.edu \\ Haitham Hadidi \\ University of Nebraska-Lincoln, haitham.hadidi@huskers.unl.edu \\ Cody Kanger \\ University of Nebraska-Lincoln, ckanger93@gmail.com \\ X. L. Yan \\ University of Nebraska-Lincoln, xyan@unl.edu \\ Bai Cui \\ University of Nebraska-Lincoln, bcui3@unl.edu
}

See next page for additional authors

Follow this and additional works at: https://digitalcommons.unl.edu/mechengfacpub

Part of the Mechanics of Materials Commons, Nanoscience and Nanotechnology Commons, Other Engineering Science and Materials Commons, and the Other Mechanical Engineering Commons

Sealy, Michael P.; Hadidi, Haitham; Kanger, Cody; Yan, X. L.; Cui, Bai; and McGeough, J. A., "Glocal integrity in 420 stainless steel by asynchronous laser processing" (2019). Mechanical \& Materials Engineering Faculty Publications. 385.

https://digitalcommons.unl.edu/mechengfacpub/385

This Article is brought to you for free and open access by the Mechanical \& Materials Engineering, Department of at DigitalCommons@University of Nebraska - Lincoln. It has been accepted for inclusion in Mechanical \& Materials Engineering Faculty Publications by an authorized administrator of DigitalCommons@University of Nebraska Lincoln. 
Authors

Michael P. Sealy, Haitham Hadidi, Cody Kanger, X. L. Yan, Bai Cui, and J. A. McGeough

This article is available at DigitalCommons@University of Nebraska - Lincoln: https://digitalcommons.unl.edu/ mechengfacpub/385 


\title{
Glocal integrity in $\mathbf{4 2 0}$ stainless steel by asynchronous laser processing
}

\author{
M. P. Sealy, ${ }^{1}$ H. Hadidi, ${ }^{1}$ C. J. Kanger, ${ }^{1}$ \\ X. L. Yan, ${ }^{1}$ B. Cui, ${ }^{1} \&$ J. A. McGeough ${ }^{2}$ \\ 1 Department of Mechanical and Materials Engineering, \\ University of Nebraska-Lincoln, Lincoln, NE 68588, USA \\ 2 School of Engineering, The University of Edinburgh, \\ Edinburgh EH9 3FB, UK \\ Corresponding author - M. P. Sealy, email sealy@unl.edu
}

\begin{abstract}
Cold working individual layers during additive manufacturing (AM) by mechanical surface treatments, such as peening, effectively "prints" an aggregate surface integrity that is referred to as a glocal (i.e., local with global implications) integrity. Printing a complex, pre-designed glocal integrity throughout the build volume is a feasible approach to improve functional performance while mitigating distortion. However, coupling peening with AM introduces new manufacturing challenges, namely thermal cancellation, whereby heat relaxes favorable residual stresses and work hardening when printing on a peened layer. Thus, this work investigates glocal integrity formation from cyclically coupling LENS ${ }^{\circledR}$ with laser peening on 420 stainless steel.
\end{abstract}

Keywords: Additive manufacturing, Surface integrity, Laser peening

Published in CIRP Annals—Manufacturing Technology (2019)

doi 10.1016/j.cirp.2019.04.105

Copyright ( $)$ 2019. Published by Elsevier Ltd on behalf of CIRP. Used by permission.

Published 4 May 2019. 


\section{Introduction}

Substandard properties and poor performance remain a critical technical barrier to more widespread adoption of metal additive manufacturing (AM) technology. Current 3D metal printers lack the capability to enhance mechanical properties while printing a part. As metal powders melt, the resulting mechanical properties are highly dependent on the thermal loads induced by the heat source and the print "recipe," which includes conventional print process parameters, such as speed, spot size, and material deposition rate. Apart from fine-tuning a print recipe, there is currently no in situ method to improve the strength, corrosion resistance, and fatigue life throughout an entire build volume. Therefore, the next evolutionary step in AM is integrating surface treatments layer-by-layer to effectively print three-dimensional mechanical properties throughout an entire build volume rather than post-processing [1]. Access to individual layers has enabled a new generation of smart hybrid additive manufacturing (hybrid- AM) technologies for critical, high value components and is a promising future research direction in metal AM [2]. Traditional surface treatments, such as peening or rolling, are capable of cold working individual layers (or multiples thereof) to form an aggregate surface integrity. Locally modifying layers with surface treatments has global implications for performance. The following section provides a framework for defining glocal integrity (i.e., local with global implications) as an aggregate surface integrity.

\subsection{Surface integrity}

The term surface integrity was first introduced in 1964 by Michael Field and John F. Kahles of Metcut Research Associates, Inc. in Cincinnati, Ohio, U.S.A. to account for highly stressed and damaged surfaces on workpieces from machining [3]. More emphasis was placed on altered surface features caused by thermal, chemical, electrical, and mechanical loads. In a 1971 CIRP Keynote, Field and Kahles further elaborated on surface integrity to be comprised of two primary components: (1) surface texture, which included topography and thereby roughness (i.e., exterior features) and (2) surface metallurgy that focused more on the modified surface layer (i.e., interior features) [4]. The next significant contribution was emphasizing the connection between the modified layer and the resulting performance of a part $[5,6]$. A comprehensive definition of surface integrity is the "study and control of the [surface and] subsurface layer

and any changes in it as a result of processing that may influence the 
performance of the finished part or product" [7]. Common measures of surface integrity include roughness, residual stress, hardness, and microstructure [6]. It is important to highlight that surface integrity is a threedimensional phenomenon characterized across multiple length scales and extending several millimeters below an external surface. The depth of penetration is dependent on the manufacturing process and the respective process parameters. Beyond the maximum affected depth, bulk properties exist. Since surface integrity historically pertains to the final surface, there exist a need to define a compounding surface integrity on a temporary surface.

\subsection{Glocal integrity}

With additive manufacturing (AM), temporary surfaces are exposed for secondary processing to create a layer-by-layer aggregate surface integrity. That is, each layer in a build volume is capable of being secondarily processed to impart a unique surface integrity. As printing continues, the surface integrity in an individual layer combines with previously modified layers to create a complex glocal integrity throughout the entire build volume (Fig. 1). Local changes within single layers accumulate and affect global behavior. Tailored mechanical, physical, and chemical properties from processing are no longer limited to external surfaces. Each layer in the build is capable of a unique, temporary surface integrity that evolves into a final glocal integrity.

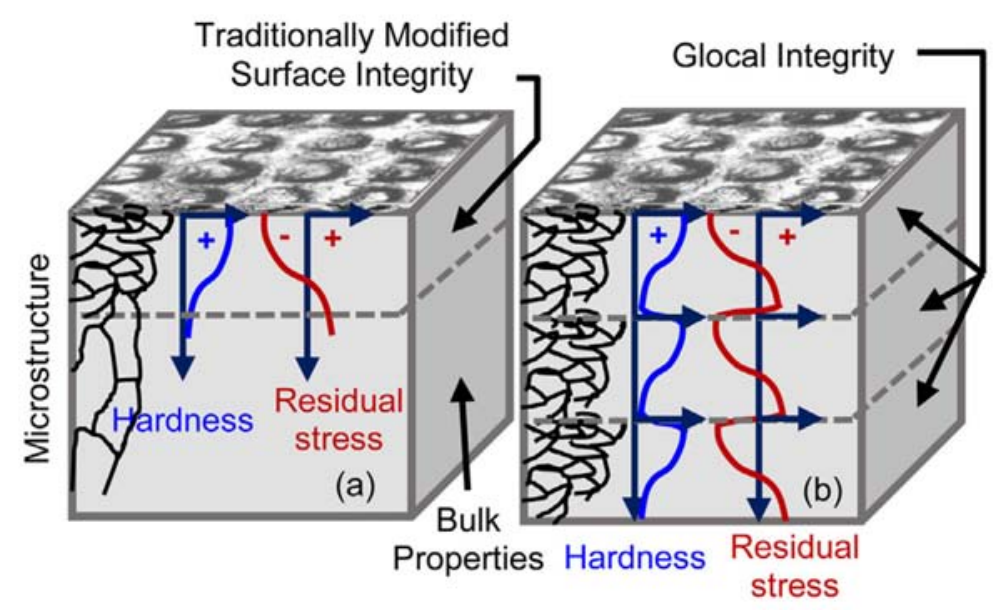

Fig. 1. Modified mechanical and material properties by (a) traditional surface treatment that only affects the near surface and (b) asynchronous hybrid additive manufacturing coupling printing and peening of sequential layers to form a glocal integrity throughout the entire build volume. 


\subsection{Achieving a glocal integrity by hybrid additive manufacturing}

Hybrid additive manufacturing (hybrid-AM) includes multiprocess, -material, -structure, -function, and -machine platform. Integrating secondary processes with additive manufacturing is a promising approach to create a unique glocal integrity throughout a build volume. HybridAM processes are defined as "the use of AM with one or more secondary processes or energy sources that are fully coupled and synergistically affect part quality, functionality, and/or process performance" [8]. Fully coupled indicates processes cannot be separated. For example, layer-by-layer peening is fully coupled since peening occurs between printed layers. If peening occurred after completing the entire build, that would be postprocessing and would not meet the fully coupled criterion. It should be noted that fully coupled is location and time independent. For hybrid-AM processes, location and time of the secondary process are irrelevant. The use of "same time" or "same location" allows for open interpretation of the definition of hybrid-AM processes. This research focuses on combining printing and out-of-envelope peening that was not simultaneous. The other distinguishing aspect of this approach compared to CIRP's definition of hybrid manufacturing processes focuses on improving the part and its performance rather than the primary AM process [9].

Analogous to surface integrity, there are interdependent links between the hybrid-AM process, glocal integrity, and the resulting performance. There are limited studies investigating process-property-performance triangle in hybrid-AM. Laser re-melting individual layers during powder bed fusion (PBF) decreased roughness while also increasing density [10]. The limitation of this approach is the inability to cold work individual layers. A similar problem exist with wire-arc additive manufacturing (WAAM) coupled with layer-by-layer hot rolling [11]. Hot rolling showed 5\%-10\% improvements in strength and elongation via grain refinement over WAAM-only and wrought samples. Alternatively, coupling WAAM with cold rolling showed substantial grain refinement, mitigated residual stress and distortion, increased strength, and improved fatigue life $[12,13]$. Although effective in terms of cold working, limitations exists with profiled rolling or inverted rolling of geometries that are more complex. The innate size constraints of some roller configurations add another barrier. An alternative approach is laser peening that requires only line-of-sight. Coupling PBF with laser peening every tenth layer on steel layer exhibited a more sustained compressive residual stress band compared to peening every layer [14]. The inherent differences between 


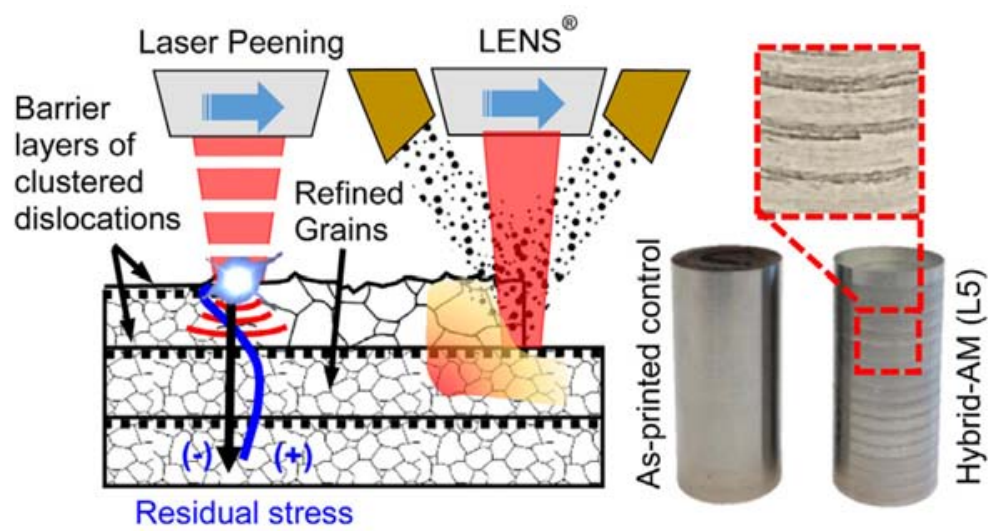

Fig. 2. Asynchronous hybrid additive manufacturing that combines laser engineered net shaping (LENS ${ }^{\circledR}$ ) with laser peening (LP). Powder is deposited and melted on the first pass and peened on the second pass.

melt pool size and process mechanics between PBF and LENS ${ }^{\circledR}$ are expected to affect redistribution of residual stress.

The objective of this study was to apply the method of spatial surface treatments to the field of additive manufacturing to isolate how strengthening mechanisms and residual stress caused by interspersing peened layers (i.e., barrier layers) inhibit dislocation motion and affect mechanical properties (Fig. 2). More specifically, this study determined if interspersing peened layers during LENS ${ }^{\circledR}$ on 420 stainless steel created hierarchically modified layers that inhibit dislocation motion through the physical phenomenon of work hardening, grain refinement, and residual stress. Laser peening is a mechanical "hammering" process that cold works the surface. The resulting glocal integrity from cyclically printing and peening was measured across multiple length scales with microhardness, residual stress, and micro-/nanostructure. This approach differentiates itself from existing strategies to improve the printability and strength of alloys through its focus on hybrid processing as compared to alloy development or traditional surface modifications. Challenges with asynchronous laser processing include thermal cancellation of favorable mechanical properties when cyclically coupling LENS ${ }^{\circledR}$ with laser peening.

\subsection{Challenges in hybrid-AM: Thermal cancellation}

One primary challenge includes how to avoid thermal cancellation of favorable 3D mechanical properties from LENS ${ }^{\circledR}$, i.e., understand how heat from printing relaxes or redistributes favorable mechanical properties on previously peened layers. Thermal cancellation occurs when a new layer 


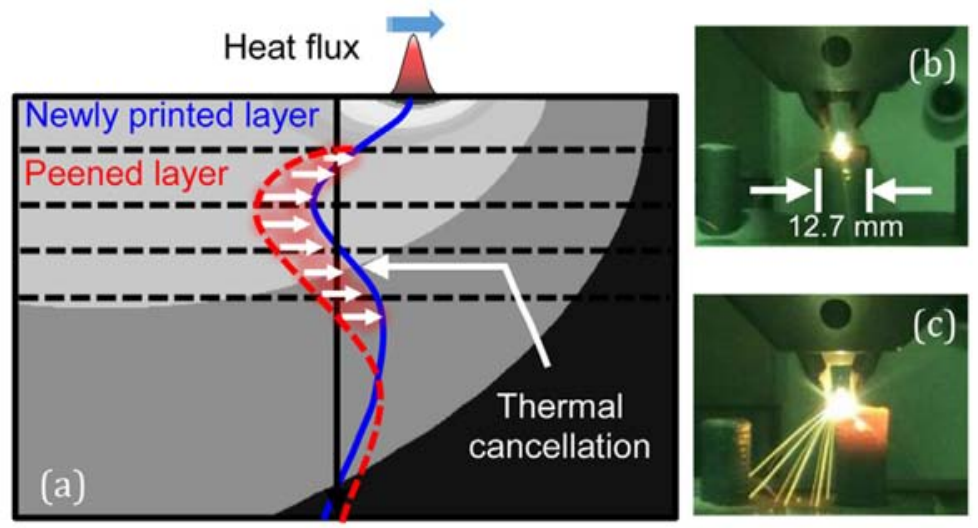

Fig. 3. (a) Thermal cancellation of compressive residual stress from an applied heat flux when a new layer is added on a previously peened layer. Comparison of the thermal penetration depth from LENS ${ }^{\circledR}$ of 420 stainless steel cylinders with laser power at (b) $400 \mathrm{~W}$ and (c) $600 \mathrm{~W}$.

is added on a peened surface (Fig. 3). Heat generated during material deposition has the potential to cancel beneficial mechanical properties previously induced by peening. The phenomenon of eliminating, reducing, or redistributing favorable mechanical properties from heat during printing is referred to as "thermal cancellation" [15].

Naturally, thermal cancellation is dependent on AM process parameters and the corresponding heat entering the workpiece. For example, the thermal penetration depth from LENS deposition of 420 stainless steel increased $300 \%$ when laser power increased from $400 \mathrm{~W}$ to $600 \mathrm{~W}$ (Fig. 3). The degree of sensitivity depends on the printed material and its thermal properties. Furthermore, it is important to highlight that thermal cancellation is AM process dependent. The melt pool in LENS ${ }^{\circledR}$ is comparatively larger than in powder bed fusion. Thus, LENS ${ }^{\circledR}$ has a greater potential for complete thermal relaxation and redistribution of favorable mechanical properties throughout the build volume.

\section{Asynchronous laser processing procedure}

Micro-Melt 420 stainless steel powder from Carpenter Powder Products (Bridgeville, PA) was asynchronously printed and laser peened out of envelope on an Optomec LENS ${ }^{\circledR}$ HY20-CA directed energy deposition system and Continuum Q-switched Nd:YAG pulsed laser. Powder size ranged from $45 \mu \mathrm{m}$ to $105 \mu \mathrm{m}$ and was printed on an $8 \mathrm{~mm}$ thick cold rolled steel baseplate. Printed cylinders were $12.7 \mathrm{~mm}$ in diameter 
and $25.4 \mathrm{~mm}$ tall. Each layer was printed with an outer shell and a raster pattern oriented $90^{\circ}\left(+45^{\circ} /-45^{\circ}\right)$ from the previous layer. The theoretical layer thickness was $300 \mu \mathrm{m}$ for a total of 85 layers. Samples were printed with argon shielding gas from the center purge nozzle (28 L/min) and powder delivery nozzle $(6 \mathrm{~L} / \mathrm{min})$. Laser power, scan speed, and auger speed were 390 W, 12 mm/s, and 6 RPM, respectively. Process parameters were based on Optomec's default print recipe.

Laser peening (LP) is a mechanical surface treatment to locally cold work a surface by hammering with high pressure shock waves. A Powerlite DLS 8010 laser peened at 50\% overlap and 500\% coverage for max penetration depth. The laser had a $1064 \mathrm{~nm}$ wavelength, $8 \mathrm{~ns}$ pulse width, $10 \mathrm{~Hz}$ repetition rate, and $9 \mathrm{~mm}$ beam diameter. The layer peening frequency (i.e., number of printed layers between peened layers) was five (L5). Laser peening energy was $700 \mathrm{~mJ}$, and the spot diameter was $1 \mathrm{~mm}$. The corresponding power density was $12.7 \mathrm{GW} / \mathrm{cm}^{2}$. Ablative and confining layers were black tape and a 1-2 mm water curtain.

\section{Glocal integrity of 420 SS from coupling LENS ${ }^{\circledR}$ and LP}

\subsection{Microhardness}

Microhardness measured the degree of work hardening and the gradient decay after cyclically coupling LENS ${ }^{\circledR}$ and LP (Fig. 4). A 200 series Wilson Tukon Microindenter mapped Vickers hardness across 75 printed layers in which 16 were laser peened. Full mapping along the entire height

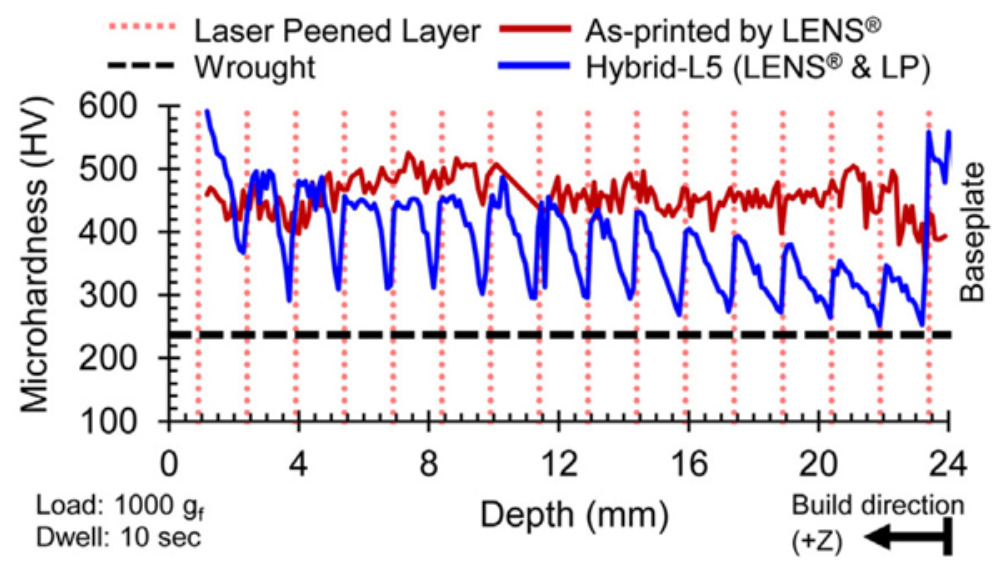

Fig. 4. Microhardness of 420 stainless steel after cyclically coupling LENS ${ }^{\circledR}$ and LP every five layers. 
provided a measure of thermal cancellation from printing on previously peened layers. Hardness oscillated according to the layer peening frequency of $L 5$, and the peak-to-valley distance gradually decreased while approaching the baseplate. At $5 \mathrm{~mm}$ below the top surface, the maximum hardness from peening was no longer greater than the as-printed hardness. Further, the width of the hybrid "peaks" converged from a steplike function to a single point deeper into the build volume. Three mechanisms driving these observations were thermal annealing from LENS ${ }^{\circledR}$ printing on a peened layer, softening from excessive peening at $500 \%$ coverage possibly leading to dynamic recrystallization, and cumulative residual stress redistribution between barrier layers.

\subsection{Microstructure}

The microstructure of 420 stainless steel shown in Fig. $\mathbf{5}$ compares the LENS ${ }^{\circledR}$ as-printed control sample to cyclically coupling LENS ${ }^{\circledR}$ and laser peening every five layers. Sample were ground using $\mathrm{SiC}$ papers with 180, 320, and 600 grit followed by polishing with diamond suspensions and $0.05 \mu \mathrm{m}$ alumina oxide powder. The etchant was Kalling's reagent (Carpenter Technology Corp.). The as-printed control exhibited slanted columnar grain growth consistent with a moving solidification front in LENS ${ }^{\circledR}$. The hybrid-L5 sample exhibited more refined equiaxed grains throughout multiple locations in the build volume. The average grain size reduced from $30 \mu \mathrm{m}$ to $10 \mu \mathrm{m}$. Results indicate thermal cancellation did not result in completely new grain formation. Therefore, designing a layer-by-layer peening sequence is a feasible approach to strengthen steel.

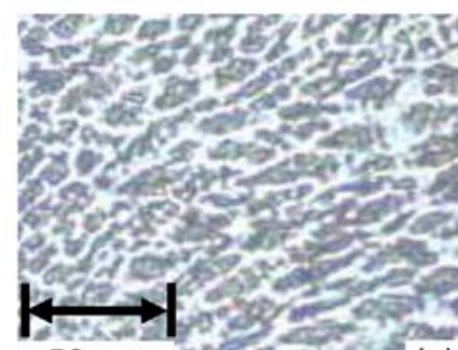

$50 \mu \mathrm{m}$

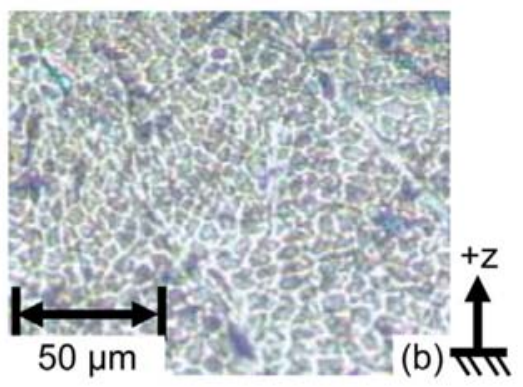

$50 \mu \mathrm{m}$

Fig. 5. Microstructure of 420 stainless steel $2.1 \mathrm{~mm}$ below the surface: (a) LENS ${ }^{\circledR}$ as-printed and (b) hybrid L5 LENS and laser peening. 


\subsection{Nanostructure}

Two transmission electron microscopy (TEM) samples of approximately $10 \mu \mathrm{m} \times 10 \mu \mathrm{m}$ were extracted from the surface of the as-printed control and hybrid L5 coupons and milled to electron transparency ( $\approx 100$ $\mathrm{nm}$ ) by focused $\mathrm{Ga}+$ ion beam in a FIB/ SEM dual-beam workstation (Helios 660 NanoLab, FEl). The surface was electrochemically polished in a solution of $5 \% \mathrm{HClO} 4$ and $95 \% \mathrm{C}_{2} \mathrm{H}_{5} \mathrm{OH}$ at $0{ }^{\circ} \mathrm{C}$ and $1 \mathrm{~A}$ in order to remove the mechanically damaged layer. The characterizations of the nanostructures were carried out by TEM (Tecnai Osiris, FEI) operated at $200 \mathrm{kV}$ (Fig. 6). Both the control and hybrid samples showed severe deformation characteristics, including the high quantities of subgrains and dislocation tangles. Severe deformation might partially be due to turning and/

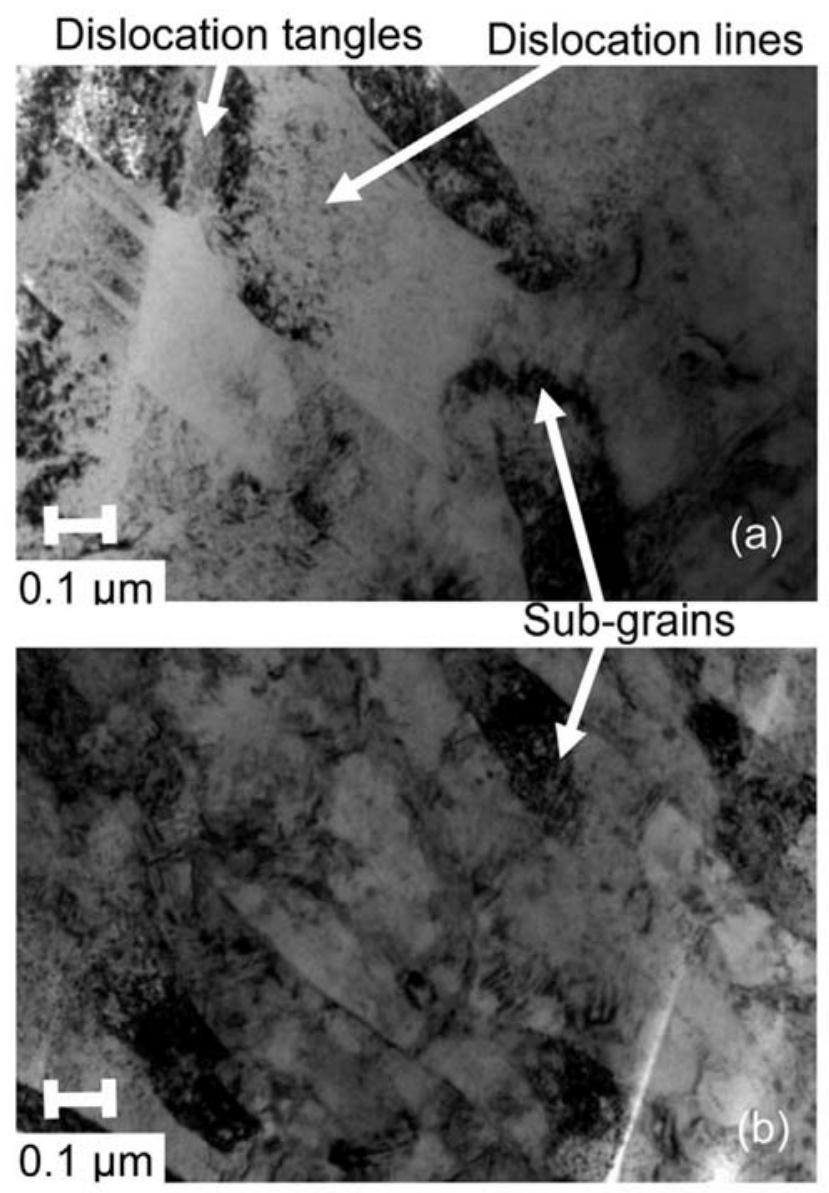

Fig. 6. Nanostructure of 420 stainless steel: (a) LENS ${ }^{\circledR}$ as-printed and (b) hybrid L5 LENS and laser peening. 


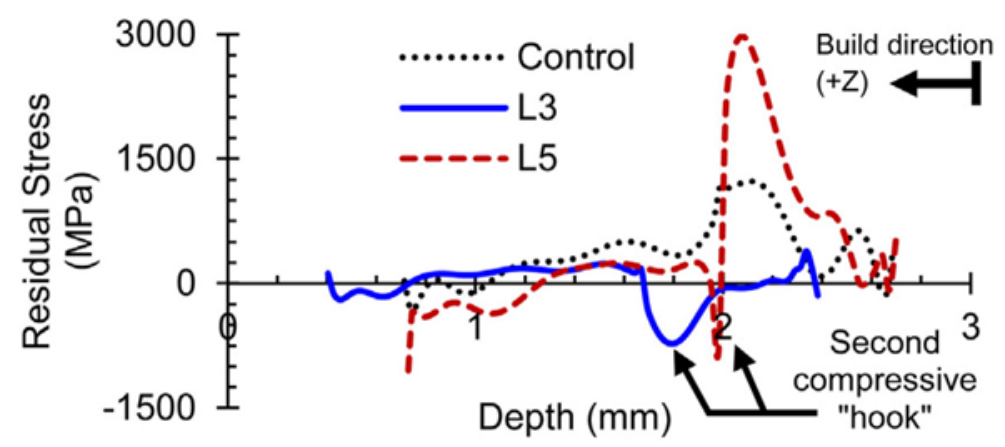

Fig. 7. Residual stress in $420 S S$ by hole drilling after cyclically coupling LENS ${ }^{\circledR}$ and LP every three layers (L3) and five layers (L5).

or printing. The sub-grain size in the hybrid L5 steel sample was $109 \pm$ $68 \mathrm{~nm}$ while that in the control sample was $157 \pm 94 \mathrm{~nm}$. The decrease of subgrain size indicated a higher stress level, i.e. more significant deformation from peening. Additionally, the dislocation density of the hybrid L5 steel sample was $6.08 \times 10^{13} \mathrm{~m}^{-2}$ compared with that of control sample being $3.07 \times 10^{13} \mathrm{~m}^{-2}$. Doubling of the dislocation density also indicates more severe plastic deformation.

\subsection{Residual stress}

A SINT Technologies MTS 3000 system measured residual stress in the vertical z-direction (i.e., build direction) via the hole drilling method (ASTM E837-13a). The spatial resolution was $25 \mu \mathrm{m}$. Approximately 400 $\mu \mathrm{m}-700 \mu \mathrm{m}$ were milled off the top surface in order to mount the $y$-series rosette strain gauge from HBM Inc. (K-CRY6-K015-1-120-4-030-N). The drilling unit had an air driven turbine that spun a SINT Technologies $1.6 \mathrm{~mm}$ cutter (1SINTCTT/1) at 400,000 RPM. The high speed spindle reduced the amount of stress imparted by the drilling process. Measurements were recorded along the depth direction up to $2 \mathrm{~mm}$ from the external surface. Results from the residual stress measurements are shown in Fig. 7.

The as-printed control sample exhibited a compressive hook from machining followed by a deep tensile residual stress band commonly associated with additive parts. The hybrid L3 condition (i.e., peening every three layers) and L5 condition (i.e., peening every five layers) exhibited a compressive hook from machining the top surface followed by a shorter tensile residual stress band. The most interesting feature of these results 
is the existence of a second compressive residual stress hook that remained below the surface. Results indicate thermal cancellation does not completely remove or redistribute favorable compressive residual stress bands that exists below the processed surface. The high tensile peak for L5 may be attributed to residual stress algorithms incapable of incorporating a second compressive hook.

\section{Summary and conclusions}

The objective of this research was to understand how thermal loads from printing affect strengthening mechanisms and residual stress formation when interspersing peened layers during LENS ${ }^{\circledR}$. Peened layers act as barriers that inhibit dislocation motion and provide compressive residual stress. The approach applied the method of spatial surface treatments, namely laser peening, on multiple layers during LENS ${ }^{\circledR}$ printing of 420 stainless steel to solve the long-term problems of distortion, substandard properties, and poor performance in metal AM.

In this study, asynchronous laser processing formed an aggregate surface integrity. The term glocal integrity (i.e., local with global implications) was defined to describe the cumulative surface integrity and its role on affecting part performance. Results showed hybrid-AM by LENS ${ }^{\circledR}$ and laser peening improves mechanical properties of 420 stainless steel by cumulative layer-by-layer cold working. Peening induced favorable compressive residual stresses and work hardening within distinct layers that caused a higher dislocation density and more refined micro- and nanostructures compared to as-printed control samples. The key conclusion from this work was that coupling LENS ${ }^{\circledR}$ deposition printing, which has a relatively large melt pool, with a cold working spatial surface treatment does not result in complete thermal cancellation of favorable mechanical properties. A second compressive residual stress hook was observed approximately $1 \mathrm{~mm}$ below the milled surface and microhardness oscillated based on the layer peening frequency. Improvements to glocal integrity reveals potential to revolutionize materials design.

Acknowledgments - The research was performed in part in the Nano-Engineering Research Core Facility and Nebraska Nanoscale Facility: National Nanotechnology Coordinated Infrastructure and the Nebraska Center for Materials and Nanoscience, which are supported by the National Science Foundation under Award ECCS: 1542182. Further, the authors would like to acknowledge Jazan University (Saudi 
Arabia) for financial support of the lead student investigator and to the Donors of the American Chemical Society Petroleum Research Fund for partial support of this research for Dr. Bai Cui. Lastly, the research was facilitated by the Laser Assisted Nano Eng. Lab under the direction of Dr. Yongfeng Lu.

\section{References}

[1] Bourell D, Kruth JP, Leu M, Levy G, Rosen D, Beese AM, Clare A (2017) Materials for Additive Manufacturing. CIRP Annals 66(2):659-681.

[2] Schmidt M, Merklein M, Bourell D, Dimitrov D, Hausotte T, Wegener K, Overmeyer L, Vollertsen F, Levy GN (2017) Laser Based Additive Manufacturing in Industry and Academia. CIRP Annals 66(2):561-583.

[3] Field M, Kahles JF (1964) The Surface Integrity of Machined-and-Ground High Strength Steels. Problems in the Load-Carrying Application of High-Strength Steels Symposium, 54-77. AD0610750.

[4] Field M, Kahles JF, Cammett JT (1972) A Review of Measuring Methods for Surface Integrity. CIRP Annals 21(2):219-238.

[5] Field M (1973) Surface Integrity — A New Requirement for Improving Reliability of Aerospace Hardware. 18th A Natl SAMPE Symp 1-27.

[6] Society of Manufacturing Engineers (1987) American National Standard: Surface Integrity ANSI B211.1-1986 1-17.

[7] Groover MP (1996) Fundamentals of Modern Manufacturing: Materials, Processes, and Systems, Prentice-Hall, New Jersey.

[8] Sealy MP, Madireddy G, Williams R, Rao P, Toursangsaraki M (2018) Hybrid Processes in Additive Manufacturing. Journal of Manufacturing Science and Engineering 140(6):1-13. pp. 060801.

[9] Lauwers B, Klocke F, Klink A, Tekkaya AE, Neugebauer R, Mcintosh D (2014) Hybrid Processes in Manufacturing. CIRP Annals 63(2):561-583.

[10] Yasa E, Kruth JP, Deckers J (2011) Manufacturing by Combining Selective Laser Melting and Selective Laser Erosion/Laser Re-melting. CIRP Annals 60(1):263-266.

[11] Xie Y, Zhang H, Zhou F (2016) Improvement in Geometrical Accuracy and Mechanical Property for Arc-Based Additive Manufacturing Using Metamorphic Rolling Mechanism. Journal of Manufacturing Science and Engineering 138 (11):1-8. pp. 111002.

[12] Colegrove PA, Donoghue J, Martina F, Gu J, Prangnell P, Hönnige J (2017) Application of Bulk Deformation Methods for Microstructural and Material Property Improvement and Residual Stress and Distortion Control in Additively Manufactured Components. Scripta Materialia 135(Suppl. C):111-118.

[13] Martina F, Roy MJ, Szost BA, Terzi S, Colegrove PA, Williams SW, Withers PJ, Meyer J, Hofmann M (2016) Residual Stress of As-Deposited and Rolled Wire +Arc Additive Manufacturing Ti-6Al-4V Components. Materials Science and Technology 32(14):1439-1448. 
[14] Kalentics N, Boillat E, Peyre P, Gorny C, Kenel C, Leinenbach C, Jhabvala J, Logé R (2017) 3D Laser Shock Peening - A New Method for the 3D Control of Residual Stresses in Selective Laser Melting. Materials \& Design 130:350-356.

[15] Sealy MP, Madireddy G, Li C, Guo YB (2016) Finite Element Modeling of Hybrid Additive Manufacturing by Laser Shock Peening. Solid Freeform Fabrication Symposium (SFF), 306-316. 